\title{
Spine deformity care: a team effort
}

\author{
Paul D. Sponseller ${ }^{1}$
}

Published online: 16 February 2021

(c) Scoliosis Research Society 2021

\begin{abstract}
This address highlights the Society's progress during the past year, with special initiatives in inter-disciplinary education, research, and increased engagement.
\end{abstract}

This address was given virtually, a lasting reminder of COVID19! We had not plan to talk this way; rather a wonderful meeting had been planned in Phoenix to provide memorable education and fellowship. Yet as Barack Obama said, "when times change, so must we", and we have. In June, your Board of Directors decided that the safest course was to convert the meeting to all-virtual and adjust the meeting times for maximal global participation. Still, this touchstone in our year provides an opportunity to take stock of where we are, and provide future direction for those listening. For those reading this, it is also a useful snapshot of the evolution of our Society. Today, I would like to discuss our biggest opportunities, and how we plan strategically to meet them. I would like to focus on inter-disciplinary education, and new ways that SRS can provide that education. I would like to summarize our approach to research, and our efforts to involve early-career surgeons in the future of SRS.

SRS leadership is dependent not on the talents of a few, but on a team of leaders sharing ideas and efforts. Profound admiration and appreciation go out to Todd Albert, Past-president 2, Peter Newton, Past President, Muharrem Yazici, President-Elect, and Chris Shaffrey, Vice President. This team volunteers a significant amount of their time and energy over a 5-year period to guide the SRS. The five Council Chairs and the six Directors-at-Large round out the Board. And it is on the 29 Committees that the real work is done; our greatest thanks for making SRS a success. A recent operational tactic is the use of task forces to tackle new challenges. These small groups study an area, devise action plans, and implement them through charges to committees. SRS task forces have transformed our approach

Paul D. Sponseller psponse@jhmi.edu

1 John Hopkins Hospital, Baltimore, MD, USA to research, our Fellowship criteria, and the availability of Pediatric Devices. New task forces are starting to tackle inter-disciplinary education, diversity, and data platforms.

The mission of the SRS is to foster the optimal care of all patients with spinal deformities. This leads directly to our vision that our global leadership in research and education will result in significantly enhanced quality of life for all patients with spinal deformities. Since a large part of our activity involves education, we aim to provide timely, relevant, culturally diverse educational content for professionals to enhance understanding and outcomes for patients with spinal deformity. The Society is guided by a strategy which spans multiple years. Every 3-3 years, we update this plan. This year we held a Strategic Planning session in January in Dulles, Virginia. We developed strategies to improve our global reach, our early-career surgeon engagement, and our inter-disciplinary education. The new task forces listed above were created during this meeting.

This year we are making a conscious effort to increase our diversity in all dimensions, making sure that our programs involve as broad a representation of our members as possible. A task force on diversity (formally titled the diversity, equity, and inclusion task force) is working on this area. The Needs Assessment Task Force will diversity education across specialties as well.

\section{Education}

Both of our major meetings needed to be re-formatted this year. Our 27th IMAST, scheduled for April 1-4 in Athens, was formally canceled by the Greek government with just weeks to spare. The IMAST committee led by Han Jo Kim worked quickly to redesign it to eight live virtual sessions over the summer. We were able to engage 1300 virtual 
registrants this year-our biggest so far-with a mean of $12 \mathrm{~h}$ of viewing each. It is already clear that our 2021 IMAST will also be virtual, presented over April 22-24, led by Dave Skaggs, Ahmet Alanay and Stefan Parent.

Our 2020 Annual meeting was planned to be $28 \mathrm{~h}$ of inperson content in Phoenix over 4 days (representing hundreds of hours of thoughtful arrangement by Program and Education Committees). As mandated by COVID considerations, it was transformed to $15 \mathrm{~h}$ of live virtual education over 5 days and the rest of the content made available as "self-paced" viewing on our website. We experimented with different times to determine best live viewing appeal for our global audience across 12 time zones. Our Pre-meeting Course, organized by Baron Lonner, was entitled "Interdisciplinary Care for Optimizing Outcomes in the Patient with Spinal Deformity". Many of the inter-disciplinary experts were enlisted by our local hosts, Greg White and Michael Chang.

A new and ongoing feature of both meetings will be earlycareer surgeon offerings. The goal of these sessions is to welcome and engage younger SRS members, candidates, and spine fellows. We need to harness their talents for the Society. This will be done through special sessions which include case discussions, career development discussions, and adding networking/social events as soon as feasible. We would like to thank Brian Smith, Bob Cho, Kariman AbelinGenevois, Kenny Kwan, and Caglar Yilgor for work on this exciting initiative.

\section{Interdisciplinary connections}

My clinical career has focused on spine deformity in neuromuscular disorders and genetic disorders such as Marfan Syndrome, defining their natural history and treatment differences. Many systems and specialists are involved in the care of these patients. I have been impressed that a challenge is for all disciplines to understand spine-based decisionmaking, and to make clinical decisions from evidence.

The fact that spine deformity care is a team effort is shown by the recent global adoption of spine surgical teams, preoperative optimization teams, and research teams. We need to improve education of and by team members on issues that our patients bring to us. Some examples make this real.

- Infections with implants often bring up the question of whether this is "osteomyelitis" and whether the implant needs to be removed.

- Anesthetic principles unique to spine deformity surgery are important to understand. What are the implications of different anesthetic techniques for blood pressure, cord perfusion, and neuromonitoring? How can we develop and educate our dedicated spine teams of nurses and anesthesiologists?

- From a pulmonary perspective, what are the effects of spine deformity on large and small airways and on ventilation? Furthermore, what are the effects of deformity on cardiac function?

The Needs Assessment Task Force, led by Haluk Berk, is devising ways to educate interested inter-disciplinary members. One step is to identify key principles each needs to know, and how to reach and to communicate effectively. The SRS has also developed a fund for implementation of inter-disciplinary education. An example of the enormous value of inter-disciplinary collaboration was the Harrington Guest Lecture by pulmonologist Greg Redding, summarizing his decades-long work with Bob Campbell and others in early-onset scoliosis.

There are at least three main challenges to inter-specialty collaboration and education.

1. Specialties tend to develop their own technical vocabularies, which require extra clarification when used outside the usual circles.

2. It is also important to focus on what is "needed to know" for another discipline. For instance, an anesthesiologist may not need to understand curve classification but definitely needs to have a sense for curve features which may impair intra-operative pulmonary function. Both specialties need to understand the role of perioperative multi-modal pain control. We need to define "consensus knowledge".

3. Different health-care specialties also have different learning styles and customs. For example, a large fraction of new knowledge about scoliosis care is vetted through scientific presentations and personal discussions in our closely knit field at the Annual Meeting of the SRS. Other team specialties may learn more by smallgroup or instructional methods.

Virtual platforms may allow us to enlarge target and our audiences, and reach those who may not attend our meetings. An exciting initiative is the SRS iExperience learning program spearheaded by Muharrem Yazici. This is a carefully - crafted program which can be completed anywhere and at any time. Starting with early-onset scoliosis, it will grow with modules in all areas of spine deformity under the guidance of the Blended Learning Task Force.

Cross-disciplinary collaboration may also allow us to advocate more effectively for our patients in seeking appropriate coverage for braces, therapy, and surgery. Another goal is also to advocate for more spinal deformity research funding allocation by study sections in national health institutes. 


\section{Research}

Research is our middle name. Under the guidance of Marinus deKleuver who lead the Research Task Force, the Society has started a more directed program of research. In addition to our tradition of funding some member ideas and providing a platform for their presentations, we have begun Research Agenda Setting process. This involves working with participants in many domains to identify the most important spine deformity topics to investigate. We will prioritize them and provide larger research grants in support of those on a 3-year cycle. The first example of this is the recent collaboration with POSNA and OREF to fund two of our largest-ever grants on the topic of the Growing Spine. We have also organized major support for the Adult Symptomatic Lumbar Scoliosis study, a prospective comparison of operative and non-operative treatments which is the most comprehensive study of its kind. Finally, we have been fortunate to receive support for member projects from two additional foundations, Cotrel for basic science and Biedermann for innovation.

\section{Final thoughts}

I have been fortunate to learn from many prior SRS Presidents. Some have been my teachers during training and practice: Denis Drummond, John Hall, Vern Tolo and John
Kostuik. Others have taught me in other ways, Behrooz Akbarnia in the Growing Spine Foundation, and Peter Newton, Randy Betz, Harry Shufflebarger and Al Crawford in the Harms Study Group. My biggest inspiration has been my students at all levels, who bring dedication, talent and fresh insights which will make us an even better Society for deformity care.

The impact of COVID19 has clearly been challenging reformatting meetings, straining our finances. But it has also provided an opportunity to increase our virtual outreach, as our increased IMAST viewership showed. This will also help us to reach new audiences.

2020 marked the well-deserved retirement of Tressa Goulding. She spent 30 years guiding us out of Rosement, into EDI, and into globalization. We are pleased to make her an Honorary SRS member. She has also made it a priority to select a talented Staff at EDI, led by Ashtin Neuschafer, to carry on seamlessly.

It has been an honor to serve you as SRS President, and to pass the Society on to the capable leadership of Muharrem Yazici. Thanks for your outstanding efforts!

Publisher's Note Springer Nature remains neutral with regard to jurisdictional claims in published maps and institutional affiliations. 